Zmelonek-Znamirowska Anna, Wolder Daniel, Komar-Gruszka Karolina, Gruszka Jakub, Zwierzyńska Anna, Adamczyk-Gruszka Olga. Congenital cataract. Journal of Education, Health and Sport. 2021;11(12):190-196. eISSN 2391-8306. DOI http://dx.doi.org/10.12775/JEHS.2021.11.12.012

https://apcz.umk.pl/JEHS/article/view/JEHS.2021.11.12.012

https://zenodo.org/record/5783848

The journal has had 40 points in Ministry of Education and Science of Poland parametric evaluation. Annex to the announcement of the Minister of Education and Science of December 1, 2021. No. 32343. Has a Journal's Unique Identifier: 201159. Scientific disciplines assigned: Physical Culture Sciences (Field of Medical sciences and health sciences); Health Sciences (Field of Medical Sciences and Health Sciences).

Punkty Ministerialne z 2019 - aktualny rok 40 punktów. Zalącznik do komunikatu Ministra Edukacji i Nauki z dnia 1 grudnia 2021 r. Lp. 32343. Posiada Unikatowy Identyfikator Czasopisma: 201159. Przypisane dyscypliny naukowe: Nauki o kulturze fizycznej (Dziedzina nauk medycznych i nauk o zdrowiu); Nauki o zdrowiu (Dziedzina nauk medycznych i nauk o zdrowiu).

(1) The Authors 2021;

This article is published with open access at Licensee Open Journal Systems of Nicolaus Copernicus University in Torun, Poland

Open Access. This article is distributed under the terms of the Creative Commons Attribution Noncommercial License which permits any noncommercial use, distribution, and reproduction in any medium, provided the original author (s) and source are credited. This is an open access article licensed under the terms of the Creative Commons Attribution Non commercial license Share alike. The authors declare that there is no conflict of interests regarding the publication of this paper.

Received: 25.11.2021. Revised: 30.11.2021. Accepted: 15.12.2021.

\title{
Congenital cataract
}

\section{Zaćma wrodzona}

\section{Anna Zmelonek-Znamirowska}

Department of Gynaecology and Obstetrics, Provincial Integrated Hospital in Kielce https://orcid.org/0000-0002-6610-7965

\section{Daniel Wolder}

Department of Gynaecology and Obstetrics, Provincial Integrated Hospital in Kielce https://orcid.org/0000-0001-6418-8725

\section{Karolina Komar-Gruszka}

Ophthalmology Department, Prof. Jan Bogdanowicz Children's Hospital in Warsaw, Poland https://orcid.org/0000-0002-8560-6794

\section{Jakub Gruszka}

II Department and Clinic of Obstetrics and Gynaecology, Medical University of Warsaw, Poland https://orcid.org/0000-0001-9701-4502

\section{Anna Zwierzyńska}

Collegium Medicum, Jan Kochanowski University, Kielce, Poland https://orcid.org/0000-0002-4913-8620

\section{Olga Adamczyk-Gruszka}

Department of Gynaecology and Obstetrics, Collegium Medicum, Jan Kochanowski University, Kielce; Department of Gynaecology and Obstetrics, Provincial Integrated Hospital in Kielce https://orcid.org/0000-0003-1295-009X 


\section{STRESZCZENIE}

Zaćma, inaczej katarakta to choroba oczu polegająca na zmętnieniu soczewki i związaną z tym częściową lub całkowitą ślepotę. Jest ona często występującą uleczalną przyczyną ślepoty u dzieci [1]. Częstość występowania katarakty u dzieci na świecie wynosi od 1 do 15 na 10 000. W krajach rozwiniętych częstość występowania wynosi 1 do 3 na 10000 [2]. Zaćma może zostać wykryta za pomocą prenatalnego badania USG wykonanego pomiędzy 18. a 20. tygodniem ciąży $[3,4,5]$. Wczesne wykrycie zaćmy i szybka interwencja mają kluczowe znaczenie w rozwoju prawidłowego widzenia, szczególnie u noworodków [4]. W artykule przedstawiono opis przypadku wewnątrzmacicznego ultrasonograficznego rozpoznania zaćmy wrodzonej.

Słowa kluczowe: zaćma wrodzona; ultrasonograficzna diagnostyka wewnątrzmaciczna

\section{SUMMARY}

Cataract is an eye disease that means opacification of the lens of the eye leading to partial or total blindness. It is common and treatable cause of blindness in children [1]. The prevalence of cataract in children worldwide ranges from 1 to 15 per 10,000. In developed countries, the incidence is 1 to 3 per 10,000 [2]. Cataracts can be detected using a prenatal ultrasound scan performed between 18 and 20 weeks of pregnancy [3,4,5]. Early detection of cataracts and rapid intervention are crucial in the development of normal vision, especially in newborns [4]. The article presents a case report of intrauterine ultrasonographic diagnosis of congenital cataract.

Key words: congenital cataract; ultrasonographic intrauterine diagnosis

\section{WSTĘP}

Zaćma to choroba oczu polegająca na zmętnieniu soczewki. Zmętnienia różnią się morfologią, mogą dotyczyć całej soczewki ograniczać się tylko do jej części. Choroba może mieć charakter statyczny lub ulegać z czasem progresji, może być obecna już przy urodzeniu lub 
pojawiać się we wczesnym dzieciństwie. Schorzenie to może powodować częściową lub całkowitą ślepotę [6].

Częstość występowania katarakty u dzieci wynosi od 1 do 15 na 10000 dzieci. W krajach rozwiniętych zaćmę wrodzoną rozpoznaje się u 1 do 3 na 10000 [2]. Zaćma wrodzona jest przyczyną około 10\% wszystkich przypadków utraty wzroku u dzieci. Udział zaćmy w powstawaniu ślepoty jest zróżnicowany w zależności od rejonu geograficznego [7].

Podłoże choroby może być genetyczne ( około 30\%), związane z aneuploidią lub z innymi schorzeniami ( około 30\%), infekcjami (różyczka, cytomegalia, ospa, kiła, toksoplazmoza, opryszczka, świnka) lub zaburzeniami metabolicznymi. Przyczyną zaćmy może być także długookresowe ogólnoustrojowe stosowanie glikokortykoidów lub hormonów adrenokortykotropowych. Jednostronna zaćma w 30\% jest dziedziczna. Zaćma obustronna ma podłoże genetyczne u 50\% chorych. Najczęstszym typem dziedziczenia jest typ autosomalny dominujący. Zostały również opisane rzadsze formy: typ autosomalny recesywny oraz typ związany z chromosomem X [3, 7, 8].

Prowadzone obecnie badania nad uwarunkowaniami genetycznymi zaćmy wrodzonej dotyczą mutacji w obrębie tzw. genów kandydatów oraz obszarów genomu sprzężonych $\mathrm{z}$ występowaniem tego schorzenia. Mutacje prowadzące do wystąpienia choroby wykryto w genach kodujących białka wewnątrzkomórkowe (krystaliny), białka powierzchniowe (koneksyny) i białka rozwojowe [7].

Prawidłowa soczewka jest przezierna, dwuwypukła, zdolna do utrzymania przejrzystości, załamywania światła i akomodacji. Przeźroczysta soczewka składa się z pięciu głównych warstw: jądra zarodkowego, jądra płodowego, kory, nabłonka soczewki i torebki soczewki. Przeźroczysta soczewka skupia promienie świetlne na siatkówce [7, 9].

Klasyfikacja zaćmy dziecięcej opiera się na lokalizacji zmętnień oraz na współwystępowaniu z innymi chorobami lub zespołami chorób. Najczęściej stosowane klasyfikacje uwzględniają: okres występowania, przyczynę oraz lokalizację [1].

Najczęściej występującą zaćmą wrodzoną lub dziecięcą jest zaćma warstwowa dotycząca jądra płodowego. Upośledzenie widzenia jest zależne od poziomu wysycania zaćmy w centralnej osi widzenia. Wrodzona zaćma może być obecna przy narodzinach lub rozwijać się w czasie. Niemowlęta i dzieci z rodzinną historią zaćmy z dzieciństwa powinny pilnie zostać skierowane do okulisty [10]. 
Objawy zaćmy wrodzonej u noworodków oraz niemowląt są bardzo różnorodne, m.in. leukokoria - tj. biała źrenica, objaw palcowo-oczny, oczopląs, zez, opóźniony rozwój dziecka [10]. W przypadku opóźnionej diagnozy wzrasta ryzyko nieodwracalnej ślepoty. Dzieci z zaćmą powinny przejść operację tak szybko jak to możliwe - najlepiej do 4 m.ż. [1]. Wczesne wykonanie zabiegu operacyjnego znacznie zwiększa poprawę rokowania co do rozwoju prawidłowej ostrości wzroku [3].

Zaćma może być wykryta za pomocą prenatalnego badania USG od 14. tygodnia ciąży. Soczewka w przypadku zaćmy ma zwiększoną echogeniczność. Mimo iż prenatalne ultradźwiękowe wykrywanie wrodzonej zaćmy jest możliwe, to jednak łagodna zaćma może zostać pominięta z powodu niezdolności wizualizacji soczewki lub braku oczywistej patologii w ultrasonograficznym obrazie soczewki. Poprawa obrazowania ultrasonograficznego pozwala na rozpoznanie anomalii ocznych płodu, które można łatwo pominąć w okresie poporodowym, co zapewnia kontrolę okulistyczną po urodzeniu $[3,4]$.

Ogromnym osiągnięciem na polu techniki 3D/4D jest technologia HDlive. Jest to nowatorska technika, która poprawia obrazowanie. Techniki HDlive może być używana w każdym trymestrze ciąży. Technika HDlive silhoutte tworzy gradient pomiędzy granicami organów, przestrzeniami wypełnionymi płynem i ścianami naczyń. Technika HD live podkreśla granice pomiędzy narządami o różnej echogeniczności. Kombinacja światła i cieni zwiększa głębokość percepcji i pozwala na stworzenie obrazów, które są bardziej naturalne niż przy użyciu klasycznej techniki 3D. Technologia obrazu 4D HD LIVE o niezwykłej głębi, odpowiedniemu skupieniu światła i cieniowaniu pozwala na monitorowanie poszczególnych organów rozwijającego się dziecka. Gałka oczna - ciało szkliste wraz z soczewką mogą być uwidocznione już na wczesnym stadium rozwoju embriologicznego. Nowa technologia ma duży potencjał do otwarcia nowego pola płodowej 3D sonooftalmologii [5].

\section{OPIS PRZYPADKU}

Ciężarna lat 33 w CII, PII, 28 Hbd skierowana do Kliniki Położnictwa i Ginekologii Wojewódzkiego Szpitala Zespolonego w Kielcach z powodu objawów zagrażającego porodu przedwczesnego. Dotychczasowy przebieg ciąży bez powikłań. W wywiadzie pacjentka zgłasza występowanie zaćmy wrodzonej u pierwszego dziecka oraz innych członków rodziny- dziadek ze strony ojca ojciec dzieci. Wada u pierwszego dziecka nie została zdiagnozowana wewnątrzmacicznie. Około 3 miesiąca życia matka zauważyła nieprawidłowości w rozwoju dziecka oraz nietypowy wygląd gałki ocznej. U dziecka 
rozpoznano zaćmę. Dziewczynka została poddana operacji. Wtórnie rozwinęła się jaskra. Występuje znacznego stopnia niedowidzenie. Pacjentka wymaga regularnej kontroli lekarskiej oraz ciągłej rehabilitacji.

Ciężarna przy przyjęciu do Kliniki wydolna oddechowo i krążeniowo, zgłaszała regularną czynność skurczową oraz plamienie. Badaniem napięcie spoczynkowe macicy prawidłowe. Wody płodowe zachowane. Posiew w kierunku GBS dodatni. Plamienia nie obserwowano. Szyjka miękka, skrócona. W poprzednim szpitalu pacjentka otrzymała pierwszą dawkę sterydów. W USG 2D płodu uwidocznienie obustronne zmętnienie soczewek oczu. Poza tym $\mathrm{w}$ budowie płodu nie uwidoczniono innych zmian patologicznych. Poszerzono badanie o uwidocznienie gałki ocznej oraz soczewki techniką 3D HDlive silhoutte.

a)

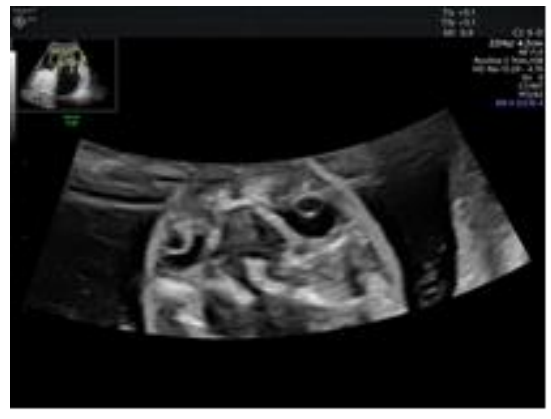

b)

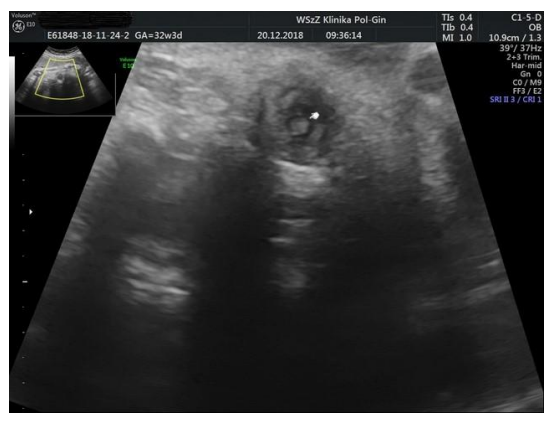

Ryc. 1. Obraz USG 2D a) prawidłowej soczewki ( widoczny hiperechogenny zarys soczewki oraz jednorodne hipoechogenne wnętrze), b) soczewki z zaćmą ( hiperechogenna obwódka oraz hiperechogenne ognisko wewnątrz soczewki zlokalizowane centralnie)

a)

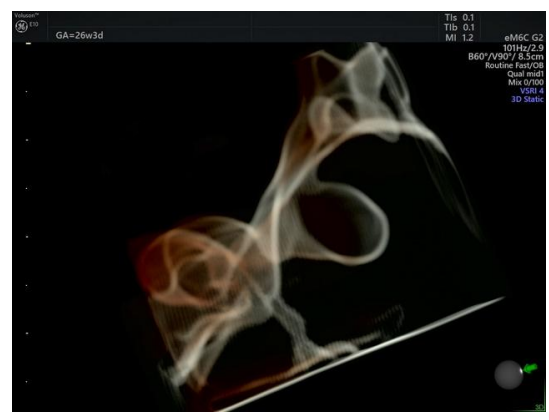

b)

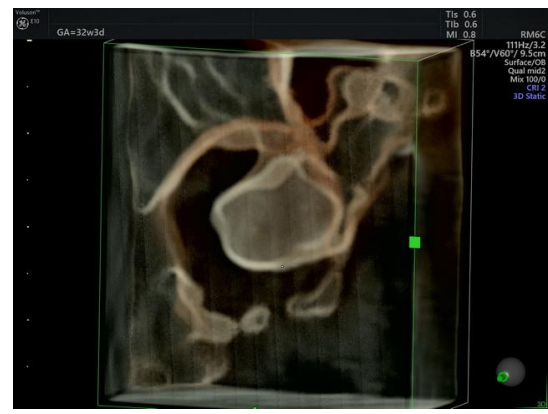

Ryc. 2. Obraz uzyskany techniką 3D HDlive silhoutte a) prawidłowej gałki ocznej i soczewki oraz b) soczewki z zaćmą. Na zdjęciach widoczna jest różnica w echogeniczności soczewek.

Podczas hospitalizacji, ze względu ma rozwinięcie się czynności skurczowej włączono tokolizę betamimetykiem oraz zastosowano neuroprotekcję siarczanem magnezu. W wyniku zastosowanego leczenia uzyskano wyciszenie czynności skurczowej mięśnia macicy. Ciąża 
zakończona porodem w 39 tygodniu. Drogą cięcia cesarskiego urodzono dziecko płci żeńskiej o masie 3120g, z pH- 7,406 oraz punktacją APGAR 10/10 punktów. Wody następowe czyste. Po porodzie zlecono konsultację okulistyczną, w której potwierdzono zmętnienie centralne soczewki. Dno oczu widoczne tylko fragmentarycznie ( szczegóły nie do oceny). Diagnoza okulistyczna- zaćma wrodzona oka prawego i lewego. Obecnie dziewczynka jest po 2 operacjach okulistycznych: wykonano usunięcie zmętniałych soczewek obu oczu wraz z witrektomią przednią. Pozostaje pod stała opieką okulistyczną.

\section{WNIOSKI}

Wczesna diagnostyka ultrasonograficzna pozwala na postawienie rozpoznania zaćmy wrodzonej. Poprawa obrazowania ultrasonograficznego techniką 2D pozwala na rozpoznanie patologii w zakresie gałki ocznej już od 14 tygodnia ciąży. Wydaje się, że w II i III trymestrze jest ona w pełni wystarczająca do oceny anatomii struktur gałki ocznej. Metoda 3D HDlive silhoutte natomiast może być wykorzystana jako badanie uzupełniające. Badanie to umożliwia uwidocznienie ciałka szklistego oraz soczewki, już na wczesnym etapie rozwoju embrionalnego i ma duży potencjał do otwarcia nowego pola płodowej 3D sonooftalmologii.

\section{References}

1. MMcCreery K., FRCOphth, FRCSI, MRCPI. Cataract in children. UpToDate 2019.

2. Foster A, Gilbert C, Rahi J. Epidemiology of cataract in childhood: a global perspective. J Cataract Refract Surg. 1997;23 Suppl 1:601-4. doi: 10.1016/s08863350(97)80040-5. PMID: 9278811.

3. Norton M. E., Scoutt L. M., Feldstein V. A. Callen's ultrasonography in obstetrics \& gynecology, Philadelphia 2017, PA: Elsevier

4. Léonard A, Bernard P, Hiel AL, Hubinont C. Prenatal diagnosis of fetal cataract: case report and review of the literature. Fetal Diagn Ther. 2009;26(2):61-7. doi: 10.1159/000238117. Epub 2009 Sep 11. PMID: 19752522.

5. Kurjak, Asim. Donald School Textbook of Ultrasound in Obstetrics \& Gynaecology. JP Medical Ltd, 2017. 
6. Francis PJ, Berry V, Bhattacharya SS, Moore AT. The genetics of childhood cataract. J Med Genet. 2000 Jul;37(7):481-8. doi: 10.1136/jmg.37.7.481. PMID: 10882749; PMCID: PMC1734631.

7. Berezowski P.; Formińska-Kapuścik M.; Filipek E. et al. Genetyka i morfologia zaćmy wrodzonej; Magazyn Lekarza Okulisty 4 (3) 2010; 141

8. Sursh KP, Wilson ME Jr. Etiology and Morphology of Pediatric cataracts. In: Wilson ME Jr, Trivedi RH, Pandey SK, eds, Pediatric Cataract Surgery; Techniques, Complications, and Management. Philadelphia, PA, Lippincott, Williams \& Wilkins, $2005 ; 6-13$.

9. Tesser RA, Hess DB, Buckley EG. Pediatric cataracts and lens anomalies. In: Harley's Pediatric Ophthalmology, 5th ed, Nelson LB, Olitsky SE (Eds), Lippincott Williams \& Wilkins, Philadelphia 2005. p.255.

10. Calhoun JH. Cataracts in children. Pediatr Clin North Am. 1983 Dec;30(6):1061-9. doi: 10.1016/s0031-3955(16)34502-3. PMID: 6646865. 